\title{
Using UAV's and BIM integration to improve infrastructure delivery - A case of Gauteng department of Infrastructure Development, South Africa
}

\author{
Innocent Musonda ${ }^{\mathrm{a}}$, Nischolan Pillay ${ }^{\mathrm{b}}$ \\ ${ }^{a, b}$ Faculty of Engineering and the Built Environment, University of Johannesburg,Doornfontein, 2094, Gauteng, SOUTH AFRICA
}

\begin{abstract}
Meeting planned timelines, quality and budget requirements in construction projects is always a challenge and the impact means that resources that should be used in other development projects get re-directed to addressing the problems created by exceeding time, quality and cost aberrations. However, the fourth industrial revolution has not spared the construction industry and it is affecting the way infrastructure is delivered. According to the World Economic Forum, digital technologies have begun to change how infrastructure and the built assets are designed, constructed, operated and maintained. The entry of technology to the industry is also driven by the realization that in order to improve on the delivery of projects, adoption of innovative methods that are based on digital technology is essential as it ensures efficiency and effectiveness in project management, transparency, and record keeping. In this study, we report on the use of drones (Unmanned Aerial Vehicles - UAV) to capture site data and how it was integrated to Building Information Modelling (BIM) models to produce as-built drawings and quality checks from comparisons with as-imagined models. Data used in the study was obtained from construction projects sponsored by the Gauteng department of infrastructure, in South Africa. Findings demonstrate that UAV and BIM technology has the potential to improve the efficiency and effectiveness of project delivery. An enhancement in monitoring of work progress during construction, site surveillance, and integration of transformed 3D models to BIM to achieve more effective project management, record keeping, and quality control were observed. The accuracy of the data was also found to be adequate for the purpose of project management tasks.
\end{abstract}

(C) 2019 The Authors. Published by Budapest University of Technology and Economics \& Diamond Congress Ltd.

Peer-review under responsibility of the scientific committee of the Creative Construction Conference 2019.

Keywords: BIM; CPM; Drones, Integration management; South Africa; UAV

\section{Introduction}

Unmanned Aerial Vehicles (UAV) had its first application in military use in the United States in times of civil war, however with recent advancement in technology the applications have broadened and now allow for civilian use. The introduction of Drone technology (UAV) has multiple uses including; Real Estate and Construction monitoring, Agriculture monitoring, Remote sensing, Commercial Aerial Surveillance, Film Making, Gas, Oil and Mineral exploration, Mapping, Relief efforts, Recreational use and a host of various other activities the mind can conceive.

UAV's in the construction industry assist Clients, Contractors and Consultants in various circumstances, namely; Progress Monitoring, Site planning, Error Resolution, Inspections, Safety and risk assessments, Aerial photography, Site and Building survey etc. The above uses, going forward in the construction industry are critical for projects of all 
Innocent Musonda \& Nischolan Pillay/ Proceedings of the Creative Construction Conference (2019) 127 https://doi.org/10.3311/CCC2019-127

sizes in the various aspects. The images and video footage also provide a method of recording critical stages in a project for further review and much later to find root cause of problems. Notwithstanding the rich data received from UAV's, it must be understood that this data does not stand alone and is more powerful when integrated with BIM solutions. UAV data integration with BIM assists in critical analysis of projects and allows for comparison between information on paper and the built product, allowing valuable decisions to be made in time and therefore negating the various risks. Noting the tremendous applications of UAV's in the construction industry, it is of utmost importance that the data is correctly interpreted to form a critical understanding of the various data sets captured from UAV's.

The Gauteng Department of Infrastructure Development (GDID) is a large organization that is tasked with delivering infrastructure projects for the South African Government in the context of the smallest but most productive province, Gauteng. On an average year, the GDID is responsible for managing, executing and delivering over three hundred infrastructure projects ranging from small schools to large hospitals. It is in this context, that the GDID promulgated the use of drone technology to monitor and manage their projects.

It was realized that in order to achieve superior results from the project monitoring exercises, appropriate tools were necessary especially that ensuring projects meet the cost, schedule and quality objectives is the goal of monitoring [7]. Consequently, the method of monitoring determines project performance. Until now traditional monitoring tools and methods have not succeeded in ensuring that projects meet their objectives and therefore project aberrations are commonplace.

This paper reports on experiences from the use of UAV in the construction industry, more especially in the fields of monitoring, management and quality control of South Africa's public sector infrastructure projects. Together with UAV Technology, the authors integrate Building Information Modelling to critically analyse infrastructure projects in terms of accuracy, quality, material usage, programme and project management. The research yielded some exciting results which are shared in this paper; however, the authors seek to determine other uses and further research going forward.

\section{Literature review}

In this section, the authors review various sources of literature to form a theoretical framework in which UAV technology operates. This section will open with a brief overview of what UAV technology is and further delve into the uses of UAV technology in the construction industry.

\subsection{What is UAV Technology?}

The term UAV refers to an aircraft that is not manned physically by a pilot but works through human involvement [6]. An Unmanned Aerial Vehicle or Drone is a technology that requires an aircraft system, i.e. multi rotor drones, fixed wing drones, single rotor helicopter, fixed wing hybrid, quadcopter among others. and a control system to operate the aircraft remotely [13]. The first uses of drones appeared for military use, but have now come with many civilian and professional use in the recent years [12]. UAV's have become a very popular tool in the construction industry as the uses far outweigh many traditional methods of reporting, monitoring, inspecting etc. [9]. Due to the ability to video record and capture photographs with geographic coordinates (X, Y, Z coordinates), UAV technologies assist in many other ways for namely; capture of objects and creation of a point cloud, accurate measuring of objects in 3D, surveying etc. [11]. Drones have incredible ability and more avenues are being opened on an ongoing basis due to software improvements, new hardware and technology etc., however what solutions does this allow for in the construction industry?

\subsection{UAV uses in Construction}

Among the various uses of UAV's, the construction industry has found some nifty uses. In this section the authors explore the various uses of UAV's associated with the construction sector. 
Innocent Musonda \& Nischolan Pillay/ Proceedings of the Creative Construction Conference (2019) 127 https://doi.org/10.3311/CCC2019-127

\subsubsection{Land Surveying}

For many years, the construction industry relied heavily on professional land surveyors to perform topographical surveys. In recent years, UAV technology has entered this space allowing consultants, clients and contractors to perform topographical surveys more often using UAV's. A surveyor is still required for professional responsibilities, however UAV's assist with quick on the go information only surveys, reducing the cost of hiring a surveyor [2]. The information extracted from a UAV survey is also near accurate with a satisfactory error of between $1 \mathrm{~cm}$ for ground control points and $4 \mathrm{~cm}$ for other parts of the survey [10].

\subsubsection{Site Inspections}

Site inspections form a part of the ongoing process of construction. With the introduction of UAV's, this has made it easier to inspect hard to reach areas of buildings [1]. All parties involved in the construction of infrastructure are seeing the benefits of UAV inspections from contractor to clients and most importantly the consultants. There is a move from manual based inspections to automated, intelligent processes that can keep record of works on site from day one [3]. The ability to have autonomous control makes UAV's easy to use and allows for inspections to be carried out more accurately [4]. From the various views on various authors, it is evident that UAV's are changing how inspections are carried out in the construction industry.

\subsubsection{Project Management}

UAV's in the construction management sector has been slow on the initial uptake, furthermore the concept is not well understood in this sector [5]. However, Zhou et al [14] argue that various academics have delved into the field of construction project management in sectors such as safety inspections, 3D modeling, aerial construction etc. UAV's can be used for various tasks, but more especially for the monitoring of progress on construction sites. This allows the project manager to have an idea of updated work on site at various time intervals, even daily if one needed it [8]. It is important for UAV technology to be adopted into the construction project management realm; further research needs to be conducted in this area to understand the benefits.

The authors of this research have concentrated primarily on three topics with reference to UAV's in the construction industry. This has been specifically coordinated as such to narrow the focus of this research.

\section{Research Methods}

This research aims to discover the benefits of UAV's and BIM on public infrastructure projects. The authors adopted the following research method.

\subsection{Task 1: Review of Literature}

In this task, the authors conduct an extensive and critical review of literature of; UAV definition and various uses of UAV's in the construction industry.

\subsection{Task 2: Research Methods}

The study took a case study approach and documents to evaluate the potential use of Unmanned Aerial Vehicles (UAV) and Building Information Modelling (BIM) to enhance project delivery. The UAV's and BIM were used to capture site data and as a basis for as-built and as-imagined/designed comparisons in construction projects. For the study, the construction of a government clinic in Gauteng was used as the case. Observations of what was achieved as well as feedback from the study team on the potential and value of using the UAV's and BIM were solicited and analysed to inform the study.

\subsection{Task 3: Analysis of Data}

The analysis of data for this research is by far the most important aspect of this paper. Although a case study approach was used, the analysis of data was made possible by an online drone mapping software. The authors found PIX4D to be the most appropriate software to analyse the data captured by the drone. The data from the drone was provided by 
Innocent Musonda \& Nischolan Pillay/ Proceedings of the Creative Construction Conference (2019) 127 https://doi.org/10.3311/CCC2019-127

the GDID and their in-house drone pilots, however the research team assisted in recommending techniques for best practices. The following best practices were recommended:

3.3.1 Many photos must be captured by the drone, nothing less than 500 photos for best results

3.3.2 The UAV must capture photos from a height of not more than $50 \mathrm{~m}$, this allowed for detailed high-resolution images.

3.3.3 Create a large overlap of photos by at least $75 \%$.

With the three best practice techniques applied, the research team sort to process and analyse the data received. Data was processed using PIX4D which created various types of outputs namely; Orthomosaic map (2D), Point Cloud (3D) and 3D textured mesh (3D). The Orthomosaic map was used to compare 2D data, i.e. overlays, CAD matching etc. which allowed the researchers to compare what was envisioned with what was currently being built on site. The point cloud data was integrated into Revit Architecture 2019 for as-built modelling and quantity take off, this was done so that in future it can be an accepted method of cross checking for payment certificates. The 3D textured mesh was used to measure materials on site and for inspection. The textured mesh is a much clearer version of the processed 3D model and allows for an in-depth inspection of various elements of the building. In the next section the authors discuss their findings of the research using the above-mentioned research and analysis techniques.

\section{Findings}

Findings from the initial concept have shown that UAV and BIM technology can be used for efficient and accurate site data collection, monitoring of work progress during construction, site surveillance, and integration of transformed 3D models to BIM or 2D CAD overlay over the UAV output to achieve more effective project management, record keeping and quality control. These aspects of the findings are presented below.

\subsection{Virtual Site Inspections}

Observations from the project team's comments indicated that the outputs from the integrated 3D models enabled inspection of the entire construction site of a government clinic much more closely than would ordinarily have been achieved with traditional inspection methods. Traditional methods of inspections afford few project team members an opportunity to inspect the constructed works more closely especially on areas that require climbing namely; roof tops, suspended slabs, beams etc. Our observation from the proof of concept, were that the methodology of using UAVs gave the entire professional project team including the client representatives, an opportunity to inspect difficult-toaccess areas such as rooftops, excavations etc. The images below were processed using PIX4D and made use of 3D textured map.

(a)

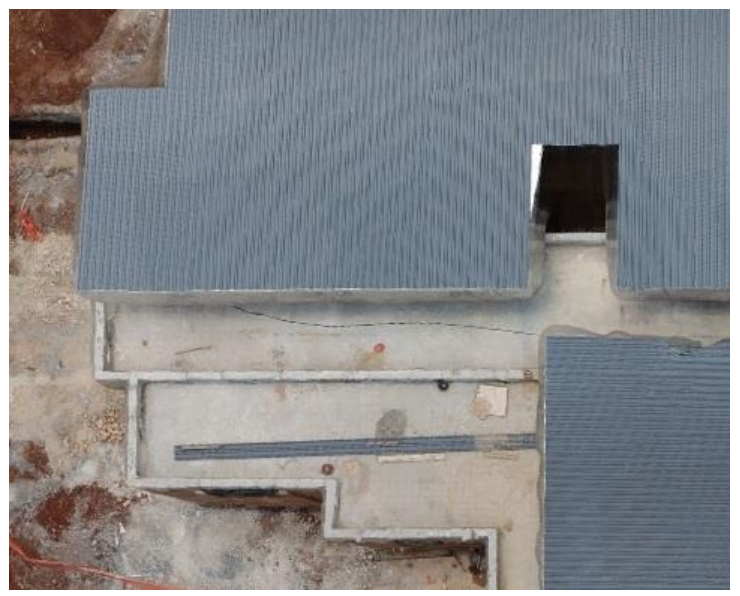

(b)

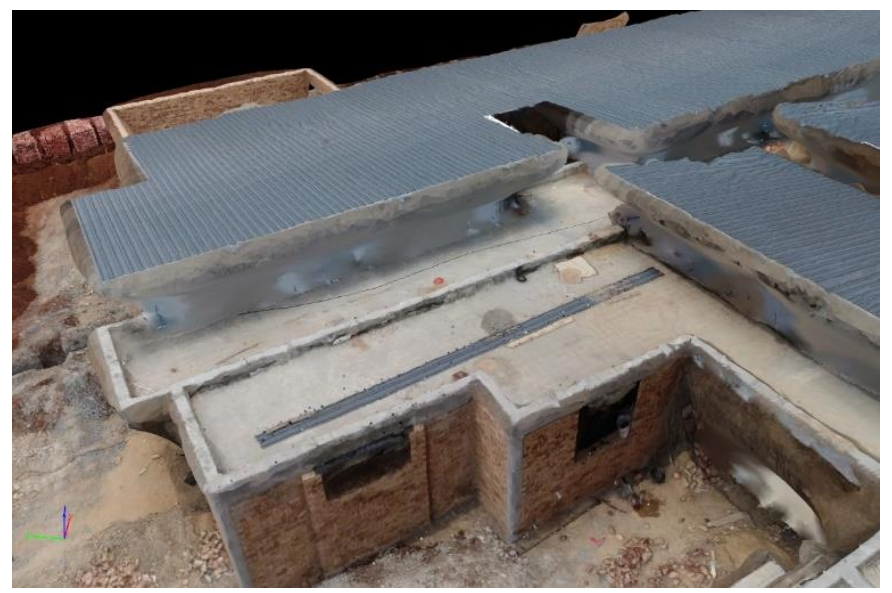

Fig. 1. (a) 2D View of slab to be inspected; (b) 3D View of slab to be inspected 
Innocent Musonda \& Nischolan Pillay/ Proceedings of the Creative Construction Conference (2019) 127 https://doi.org/10.3311/CCC2019-127

\subsection{Accuracy checking and as-builts}

The UAV output was also found to be useful for quality control purposes. The 2D CAD overlay on the UAV point cloud output revealed discrepancies between design and as built. Discrepancies included deviations from the specified measurements, increase or decrease in scope of work, and the study team was able to red flag these issues for further follow-up. The study team further observed that benefits from using the UAV output together with the BIM models, was the potential of generating the as-built drawings or models of the facilities under construction. Production of asbuilt drawings is one of the neglected aspects of the project especially in Africa.

(a)

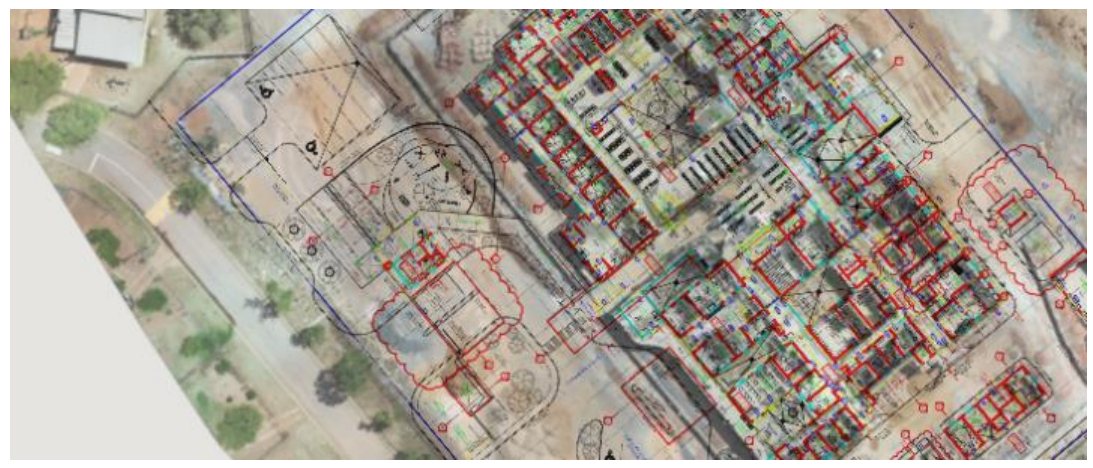

Fig. 2. (a) CAD overlay applied over Orthomosaic map

\subsection{Project Management and Quality control}

Accessing and retrieval of information relative to progress and quality control was found to be easier. Equally, the study participants expressed optimism in the methodology eliminating disputes when it comes to claims. The generated 3D models enabled clear visualisation of the building under construction and thereby enabling description of project status with ease. Orthomosaic 2D images allowed for side by side comparisons and this could be used as proof of works executed. From the below images, it is evident that UAV's can truly allow for distance working and virtual visits to sites. Furthermore, projects can now have visual tracking with Realtime data available at will.

(a)

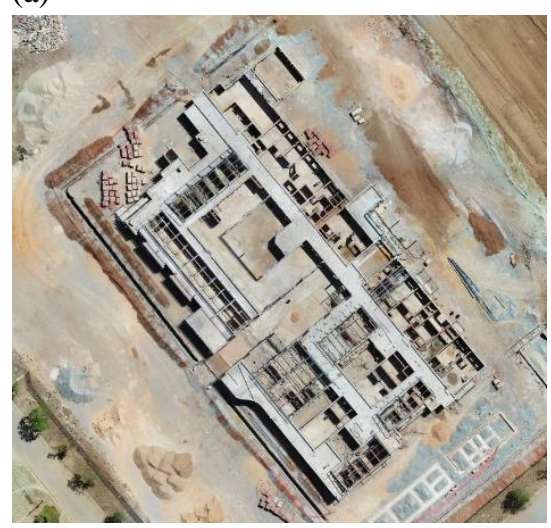

Fig. 3. (a) UAV Orthomosaic 18/10/18 (b)

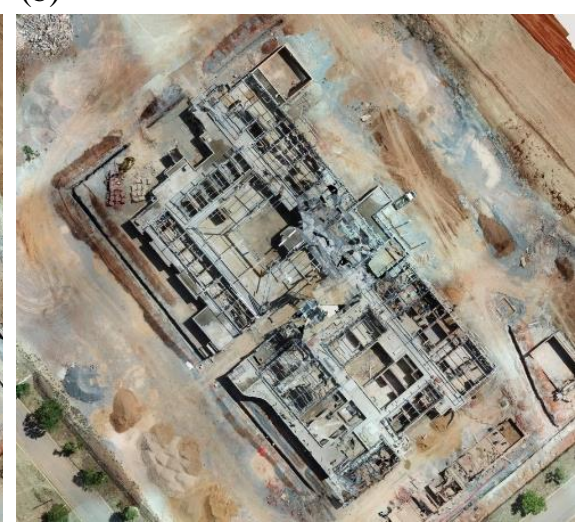

(b) UAV Orthomosaic 27/10/18 (c)

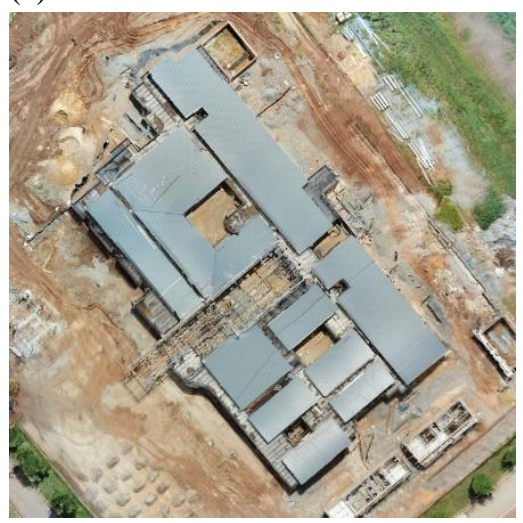

(c) UAV Orthomosaic 14/11/18

\subsection{Live measuring and BIM integration}

By far, one of the more interesting and information bearing parts of this research included live measuring of materials on site and integration with BIM to measure quantities. In the first part the authors used PIX4D to measure quantities of soil and other building materials. This is an important method to determine materials on site. By using 400 images, 
Innocent Musonda \& Nischolan Pillay/ Proceedings of the Creative Construction Conference (2019) 127 https://doi.org/10.3311/CCC2019-127

a point cloud and textured 3D mesh was created for the purposes of exploring and measuring. The data was analyzed using the desktop version of PIX4D, which the authors found to be intuitive and easy to use. Referring to Fig. 4 (a), one can see the measurement of a heap of plastering sand which has been measured. This shows the possibility to measure quantities in a 3-dimensional form, which is accurate and can determine volume. Fig. 4 (b) shows a stack of bricks that can be measured using just a visual estimation. Further to just visual measuring, the creation of a 3D model enables the user to rotate and pan to view the entire site and capture all measured work. This method is powerful and can potentially reduce error and assist with speed and also reduce the need to be physically on site.

(a)

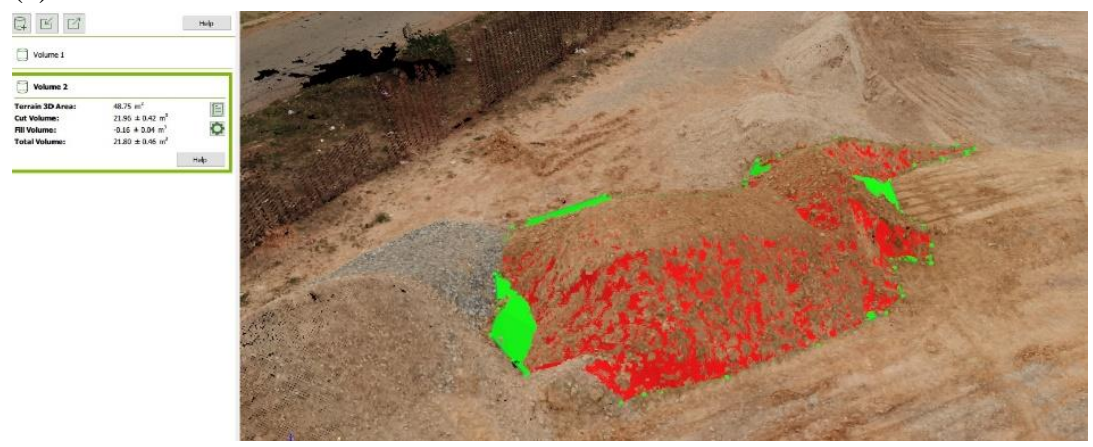

(b)

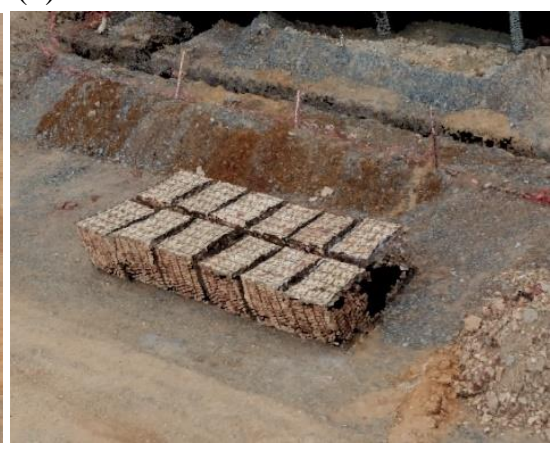

Fig. 4. (a) 3D Measurement of plastering sand on site. (b) Stack of bricks measured visually.

The use of measurement tools in BIM or from the mapper on the point clouds, was used to extract measurements to determine, the amount of work that had been done. BIM is used as a tool to measure quantities such as walls, slabs, roofs etc. The authors found that this was an accurate method to measure building elements. For the purposes of this research, the authors illustrate a small example of this method. A point cloud created in PIX4D was imported into Revit 2019 for use. Revit wall elements were traced from the point cloud as seen in Fig. 5 (a), thereafter a wall schedule was created within Revit 2019 to determine the drawn walls. Revit computed the total area of drawn walls as shown in Fig. 5(b). This method has proved that it is indeed possible to use UAV data and BIM to create a measured drawing that is accurate and live.

(a)

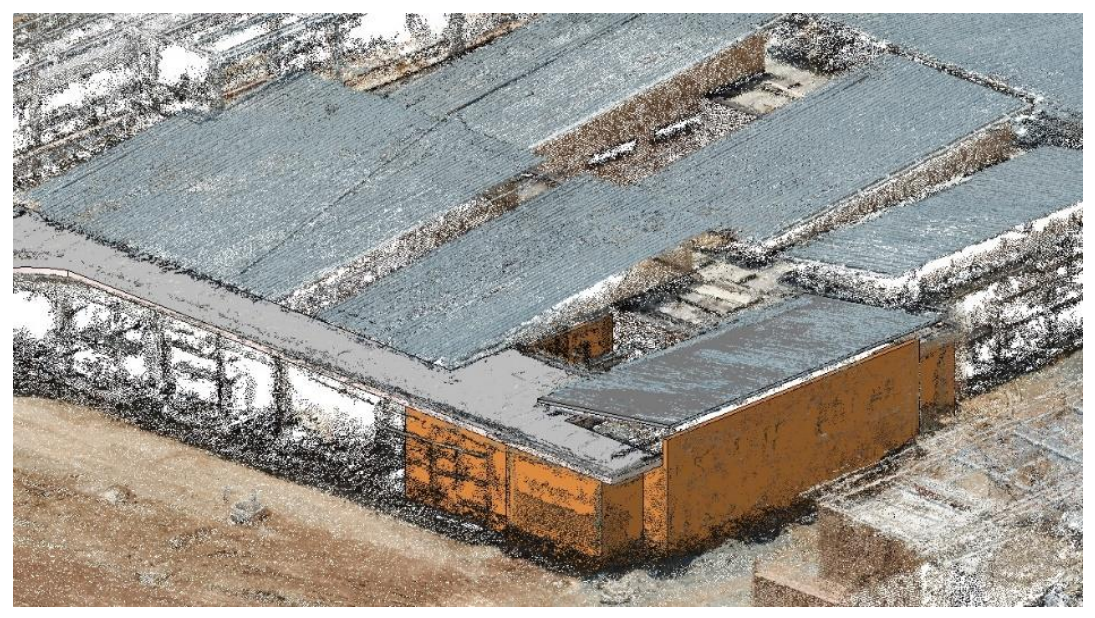

(b)

\begin{tabular}{|c|c|}
\hline \multicolumn{2}{|c|}{$<$ Wall Schedule $>$} \\
\hline A & $B$ \\
\hline Type & Area \\
\hline $230 \mathrm{~mm}$ FACEBRICK & \\
\hline $230 \mathrm{~mm}$ FACEBRICK & $60 \mathrm{~m}^{2}$ \\
\hline $230 \mathrm{~mm}$ FACEBRICK & $5 \mathrm{~m}^{2}$ \\
\hline $230 \mathrm{~mm}$ FACEBRICK & $8 \mathrm{~m}^{2}$ \\
\hline $230 \mathrm{~mm}$ FACEBRICK & $16 \mathrm{~m}^{2}$ \\
\hline $230 \mathrm{~mm}$ FACEBRICK & $2 \mathrm{~m}^{2}$ \\
\hline $230 \mathrm{~mm}$ FACEBRICK & $20 \mathrm{~m}^{2}$ \\
\hline $230 \mathrm{~mm}$ FACEBRICK & $38 \mathrm{~m}^{2}$ \\
\hline $230 \mathrm{~mm}$ FACEBRICK & $7 \mathrm{~m}^{2}$ \\
\hline $230 \mathrm{~mm}$ FACEBRICK & $14 \mathrm{~m}^{2}$ \\
\hline Grand total: 9 & $170 \mathrm{~m}^{2}$ \\
\hline
\end{tabular}

Fig. 5. (a) Walls traced from Point Cloud in Revit 2019 (b) Wall schedule with total area calculated. 
Innocent Musonda \& Nischolan Pillay/ Proceedings of the Creative Construction Conference (2019) 127 https://doi.org/10.3311/CCC2019-127

\section{Discussion and conclusions}

Findings showed that potential existed in the use of UAV - BIM integration from production of design plans, monitoring of materials on site and measuring actual work done on site. Integration of UAV and BIM technology leverages the capabilities and opportunities that the fourth industrial revolution (4IR) has provided. We can now digitalise and automate many processes and outputs in the construction process for the benefit of our industry. Therefore, the use of UAVs (Drones) and BIM technology will bring accountability and transparency in Government projects, as well as reduce the many aberrations that occur in construction projects.

The use of drones to monitor the quality and technical aspects of a project is a breakthrough for the construction industry especially if multiple projects are being run at the same time. Drones are capable of reaching hard to access spaces on construction sites. From a safety point of view, a drone mitigates the risk of injury to all parties concerned. Reports can be easily generated from the drone footage by all parties concerned.

Annual quality inspections can also be performed by a drone for the maintenance of a project long after construction is completed. A yearly 3D model can be created to monitor deterioration of the structure and methods can be implemented to maintain the building accordingly.

Benefits of sharing the drone data with clients is evident as they can see their investment progress with quality on a weekly basis without having to visit the site regularly, especially if clients are far away from the construction site.

\section{Acknowledgements}

The authors would like to acknowledge the Department of Infrastructure Development, Gauteng, South Africa for providing access to their sites and for the drone data sets. To all that contributed through time, effort and support, the authors of this paper thank you.

\section{References}

[1] Ashour, R. et al. (2017) 'Site inspection drone: A solution for inspecting and regulating construction sites', in Midwest Symposium on Circuits and Systems. Abu Dhabi: 2016 IEEE 59th International Midwest Symposium on Circuits and Systems. https://doi.org/10.1109/ MWSCAS.2016.7870116.

[2] Carvajal, F., Agüera, F. and Pérez, M. (2012) 'SURVEYING A LANDSLIDE IN A ROAD EMBANKMENT USING UNMANNED AERIAL VEHICLE PHOTOGRAMMETRY', ISPRS - International Archives of the Photogrammetry, Remote Sensing and Spatial Information Sciences, xxxviii(1/C22), pp. 201-206. https://doi.org/10.5194/isprsarchives-xxxviii-1-c22-201-2011.

[3] Chan, B. et al. (2017) 'Photogrammetric modelling and drones for the effective inspection and management of major steel truss bridges: case study', in Bridges: connecting communities: Austroads Bridge Conference, 2-6 April 2017, Melbourne, Victoria. Melbourne.

[4] Freimuth, H., Müller, J. and König, M. (2017) 'Simulating and Executing UAV-Assisted Inspections on Construction Sites', in Proceedings of the 34th International Symposium on Automation and Robotics in Construction (ISARC). Taipei. https://doi.org/10.22260/isarc2017/0090.

[5] Irizarry, J. and Costa, D. B. (2016) 'Exploratory Study of Potential Applications of Unmanned Aerial Systems for Construction Management Tasks', Journal of Management in Engineering, 32(3). https://doi.org/10.1061/(asce)me.1943-5479.0000422.

[6] Irizarry, J., Gheisari, M. and Walker, B. N. (2012) 'Usability assessment of drone technology as safety inspection tools', Electronic Journal of Information Technology in Construction, 17, pp. 194-212.

[7] Kim, C., Jeon, J. and Kim, M. . (2015) 'A Project Management System Based on the PMBOK Guide for Student-Centered Learning', International Journal of Knowledge Engineering, 1(3), pp. 185-190.

[8] Lin, J. J., Han, K. K. and Golparvar-Fard, M. (2015) 'A Framework for Model-Driven Acquisition and Analytics of Visual Data Using UAVs for Automated Construction Progress Monitoring', in 2015 International Workshop on Computing in Civil Engineering. Austin: 2015 International Workshop on Computing in Civil Engineering. https://doi.org/10.1061/9780784479247.020.

[9] McCord, M. et al. (2006) 'Roadway traffic monitoring from an unmanned aerial vehicle', IEE Proceedings - Intelligent Transport Systems, 153(1), pp. 11-20. https://doi.org/10.1049/ip-its:20055014.

[10] El Meouche, R. et al. (2016) 'UAV photogrammetry implementation to enhance land surveying, comparisons and possibilities', in International Archives of the Photogrammetry, Remote Sensing and Spatial Information Sciences - ISPRS Archives. Athens. https:// doi.org/10.5194/isprs-archives-2-W2-107-2016.

[11] Meschini, A. et al. (2014) 'Point cloud-based survey for cultural heritage. An experience of integrated use of range-based and imagebased technology for the San Francesco convent in Monterubbiano', in International Archives of the Photogrammetry, Remote Sensing and Spatial Information Sciences - ISPRS Archives. Riva del Garda, pp. 413-420. https://doi.org/10.5194/isprsarchives-XL-5-413-2014.

[12] Nisser, T. and Westin, C. (2006) Human factors challenges in unmanned aerial vehicles (uavs): A literature review, Aviation. Lund.

[13] Tatum, M. C. and Liu, J. (2017) 'Unmanned Aircraft System Applications in Construction', in Procedia Engineering. Primosten, Croatia: Elsevier, pp. 167-175. https://doi.org/10.1016/j.proeng.2017.07.187.

[14] Zhou, Z., Irizarry, J. and Lu, Y. (2018) 'A Multidimensional Framework for Unmanned Aerial System Applications in Construction Project Management’, Journal of Management in Engineering, 34(3). https://doi.org/10.1061/(asce)me.1943-5479.0000597. 